\title{
Astaxanthin supplementation enriches productive performance, physiological and immunological responses in laying hens
}

\author{
Yuanzhao Zhu ${ }^{1}$, Long Yin ${ }^{1}$, Jinshan $\mathrm{Ge}^{2}$, Xuezhuang $\mathrm{Wu}^{1}{ }^{1 *}$, Yuhan Peng ${ }^{1}$, \\ Tao Zhang ${ }^{1}$, and Meihong Jiang ${ }^{1}$
}

\section{* Corresponding Author: Xuezhuang Wu Tel: +86-151-5502-9365, \\ Fax: +86-0550-6732-040 \\ E-mail:wuxuezh@ahstu.edu.cn}

${ }^{1}$ Key Laboratory for Animal Nutritional Regulation and Health of the Anhui Province, College of Animal Science, Anhui Science and Technology University, Bengbu 233100, China

${ }^{2}$ Shandong Zhongcheng feed Technology Co. Ltd, Feicheng, 271600, China

ORCID

Yuanzhao Zhu

https://orcid.org/0000-0002-7156-9259

Long Yin

https://orcid.org/0000-0003-2822-6602 Jinshan $\mathrm{Ge}$

https://orcid.org/0000-0002-3153-4510 Xuezhuang Wu

https://orcid.org/0000-0001-7259-2517

Yuhan Peng

https://orcid.org/0000-0002-0120-668X

Tao Zhang

https://orcid.org/0000-0002-7511-4868

Meihong Jiang

https://orcid.org/0000-0001-9359-4036

Submitted Aug 4, 2020; Revised Sept 28, 2020; Accepted Nov 25, 2020
Objective: Astaxanthin is a natural super antioxidant. The present study was carried out to investigate the effect of astaxanthin rich Phaffia rhodozyma (PR) supplementation in diets on laying production performance, egg quality, antioxidant defenses and immune defenses in laying hens.

Methods: A total of five hundred and twelve 60-week-old Lohmann Brown laying hens $(2,243 \pm 12 \mathrm{~g})$ were randomly assigned to four groups, each including 4 replicates with 32 birds per replicate. Astaxanthin rich PR was added to corn-soybean meal diets to produce experimental diets containing 0 (Control), $800 \mathrm{mg} / \mathrm{kg}, 1,200 \mathrm{mg} / \mathrm{kg}$, and 1,600 mg/kg PR, respectively. The astaxanthin content in the diet was $0.96 \mathrm{mg} / \mathrm{kg}, 1.44 \mathrm{mg} / \mathrm{kg}$ and $1.92 \mathrm{mg} / \mathrm{kg}$ respectively.

Results: Results showed that dietary PR supplementation tended to increase daily feed intake ( $p=0.0512)$. There was no effect of astaxanthin rich PR on Haugh units, albumen height, egg shape index, eggshell strength, and eggshell thickness at weeks 6 ( $p>0.05)$. However, egg yolk color was significantly improved $(\mathrm{p}<0.05)$. In addition, astaxanthin rich PR supplementation significantly increased serum glutathione peroxidase and superoxide dismutase activity $(\mathrm{p}<0.05)$, increased serum immunoglobulin $\mathrm{G}$ content $(\mathrm{p}<0.05)$, and reduced malondialdehyde content $(\mathrm{p}<0.05)$ in laying hens.

Conclusion: In conclusion, astaxanthin rich PR can improve the color of egg yolk, enhance the antioxidant defenses, and regulate the immune function.

Keywords: Astaxanthin; Laying Hens; Egg Quality; Antioxidant Defenses; Immune Defenses

\section{INTRODUCTION}

Astaxanthin, also known as allophycocyanin, is found in various microorganisms and marine animals, such as Phaffia rhodozyma (PR), microalgae, salmon, krill, complex plants and some birds [1]. Natural astaxanthin is mainly extracted from seafood [2]. Astaxanthin was first extracted and identified from lobster by German Chemist Richard Kuhn in 1938. The antioxidant activity of astaxanthin is much better than other carotenoids, and its ability to scavenge singlet oxygen is 6,000 times higher than that of vitamin C [3]. According to Shimidzu et al [4], the antioxidant capacity of astaxanthin in deuterated trichloromethane is 540 times higher than that of vitamin $\mathrm{E}$ in a mixed solution of deuterated trichloromethane and deuterated methanol, astaxanthin's ability to scavenge singlet oxygen free radicals is 40 times higher than that of carotene. It is well know that astaxanthin has an important role in the prevention of atherosclerosis [5]. With the prohibition of antibiotics, astaxanthin has become a potential green additive because of its natural, non residual, antioxidant and immune function. However, there are few studies on astaxanthin application 
in animal production.

Previous studies have shown that dietary astaxanthin supplementation can improve the egg quality of hens [6] and ducks [7]. Consumers are interested in eggshell color. The color of eggshell is mainly affected by the environment and physiological conditions of the laying hens [8]. The eggshell color comes from vitellogenin, the precursor of which is carotenoid [9]. In addition, the addition of astaxanthin delayed the decrease of yolk index and yolk color [10]. Therefore, it is speculated that astaxanthin can prolong the storage time of eggs. For laying hens and Pekin ducks, astaxanthin enhanced the antioxidant capacity [7] and regulated lipid metabolism of laying hens [11]. For broilers, the addition of astaxanthin could significantly improve muscle color [12] and alleviate structural damage to the digestive system [13]. Meanwhile, the feed industry has been advised to add functional ingredients to conform with consumers' preferences. So astaxanthin has become a popular research topic.

There are two sources of astaxanthin, artificial synthesis and biological acquisition [14]. The synthetic astaxanthin is cis structure, and its bioavailability is very low [15]. The natural astaxanthin is trans structure, which has biological activity and is relatively stable. The PR is an ideal source of astaxanthin. At present, consumers are genuinely concerned about the use of additives in food, and their interest in natural substitutes is also increasing. However, there are few reports on the study of natural astaxanthin from faff yeast in laying hens.

Therefore, the purpose of this experiment was to determine the effects of dietary astaxanthin rich PR on laying performance, egg quality, antioxidant defenses and immune defenses and to evaluate the value of astaxanthin in improving yolk color.

\section{MATERIALS AND METHODS}

All procedures of this experiment were approved (ethical committee number: 202005) by the Animal Ethics Committee of Anhui Science and Technology University (Fengyang, China).

\section{Birds, diets, and experimental design}

Five hundred and twelve 60-week-old Lohmann Brown laying hens $(2,243 \pm 12 \mathrm{~g})$ were randomly divided into 4 groups. Each group had 6 replicates of 15 hens each. The birds were kept in a three-tier battery cage, each cage (width $400 \mathrm{~mm}$, length $450 \mathrm{~mm}$, height $450 \mathrm{~mm}$ ) including 4 birds. The experiment lasted for 6 weeks, with 16 hours of light and 8 hours of darkness every day. All birds were free to feed and drink. The room temperature was maintained at $18^{\circ} \mathrm{C}$ to $26^{\circ} \mathrm{C}$ and the relative humidity was between $55 \%$ and $65 \%$ via the wet curtain ventilation system.

The experimental diets were formulated according NRC
[16] recommendations for laying hens. PR was added to corn-soybean meal diets to produce experimental diets containing 0 (control), $800 \mathrm{mg} / \mathrm{kg}, 1,200 \mathrm{mg} / \mathrm{kg}$, and 1,600 mg/kg $\mathrm{PR}$, respectively. The astaxanthin content in the diet was 0.96 $\mathrm{mg} / \mathrm{kg}, 1.44 \mathrm{mg} / \mathrm{kg}$, and $1.92 \mathrm{mg} / \mathrm{kg}$ respectively. PR was provided by Xi'an Zebang Biotechnology Co., Ltd (Shanxi, China), and the astaxanthin content of PR was $1.2 \mathrm{mg} / \mathrm{kg}$. The experimental diets had the similar nutrient levels and are shown in Table 1.

\section{Data collection and sample preparation}

During the experiment period, feed intake was measured once a week. Eggs were recorded daily in each cage, including egg weight, eggs number. After the experiment, the egg production, average egg weight, daily feed intake and feed conversion ratio (total feed intake/total egg mass) were calculated for the whole experimental phase. At the end of the trial, 12 eggs per treatment ( 3 eggs/replicate) were collected and weighed. The eggs were stored at room (temperature $25^{\circ} \mathrm{C} \pm 2{ }^{\circ} \mathrm{C}$, relative humidity $55 \% \pm 5 \%$ ) for 6 days and then were measured for Haugh units (HU), eggshell strength, eggshell thickness, albumen height, egg shape index, and egg yolk color. In addition, eight birds (two birds per replicate) from treatments were selected for blood collection from the wing vein on the 21 st and $42 \mathrm{nd}$ days. Blood samples were collected and centrifuged at 3,000×g for $15 \mathrm{~min}$. Serum was

Table 1. Ingredients and diet composition (as-fed basis)

\begin{tabular}{|c|c|c|c|c|}
\hline \multirow[t]{2}{*}{ Item } & \multirow[t]{2}{*}{ Control } & \multicolumn{3}{|c|}{$\begin{array}{c}\text { Astaxanthin rich } \\
\text { Phaffia rhodozyma } \\
\text { supplemental levels (mg/kg) }\end{array}$} \\
\hline & & 800 & 1,200 & 1,600 \\
\hline \multicolumn{5}{|l|}{ Ingredient (\%) } \\
\hline Corn & 63.00 & 62.92 & 62.88 & 62.84 \\
\hline Soybean meal (48\% CP) & 20.00 & 20.00 & 20.00 & 20.00 \\
\hline Limestone & 9.00 & 9.00 & 9.00 & 9.00 \\
\hline Wheat bran & 3.00 & 3.00 & 3.00 & 3.00 \\
\hline Phaffia rhodozyma & 0 & 0.08 & 0.12 & 0.16 \\
\hline Premix ${ }^{1)}$ & 5.00 & 5.00 & 5.00 & 5.00 \\
\hline Total & 100 & 100 & 100 & 100 \\
\hline \multicolumn{5}{|l|}{ Composition (\%) } \\
\hline $\mathrm{ME}^{2)}(\mathrm{MJ} / \mathrm{kg})$ & 10.98 & 10.98 & 10.98 & 10.98 \\
\hline Crud protein & 15.30 & 15.30 & 15.31 & 15.31 \\
\hline Calcium & 3.49 & 3.49 & 3.49 & 3.49 \\
\hline Available phosphorus & 0.36 & 0.36 & 0.36 & 0.36 \\
\hline Methionine & 0.72 & 0.72 & 0.72 & 0.72 \\
\hline Lysine & 0.34 & 0.34 & 0.34 & 0.34 \\
\hline Methionine+cysteine & 0.59 & 0.59 & 0.59 & 0.59 \\
\hline Tryptophan & 0.18 & 0.18 & 0.18 & 0.18 \\
\hline
\end{tabular}

1) Provided per kilogram of diet: 11,000 IU vitamin $A ; 3,700$ IU vitamin $D_{3}$; $35 \mathrm{mg}$ vitamin $\mathrm{E}_{;} 2.45 \mathrm{mg}$ vitamin $\mathrm{K}_{3} ; 4 \mathrm{mg}$ vitamin $\mathrm{B}_{1} ; 5 \mathrm{mg}$ riboflavin; 4 $\mathrm{mg}$ vitamin $\mathrm{B}_{6} ; 4 \mathrm{mg}$ vitamin $\mathrm{B}_{12} ; 60 \mathrm{mg}$ niacin; $2.5 \mathrm{mg}$ folic acid; $0.5 \mathrm{mg}$ biotin; 20 mg pantothenic acid; 90 mg Zn; 105 mg Mn; 100 mg Fe; 8 mg $\mathrm{Cu} ; 0.88 \mathrm{mg} \mathrm{l}$; and $0.38 \mathrm{mg}$ Se.

${ }^{2)}$ Metabolizable energy was calculated based on diet composition. 
separated and stored at $-80^{\circ} \mathrm{C}$ for further analyses.

\section{Sample analyses}

At the end of the trial, the egg samples were weighed, and then the vertical length and transverse length of eggs were measured by a vernier caliper. The egg shape index was calculated by the ratio of the vertical length of the egg to the transverse length of the egg. Eggshell thickness and eggshell strength were measured using Egg shell thickness Gauge and Egg Force Reader (ORKA Food Technology Ltd, Ramat Hasharon, Israel). The albumen height, yolk color and HU were measured by Egg Analyzer (ORKA Food Technology Ltd, Israel). The concentrations of plasma immunoglobulin A (IgA, kit No H108), IgM (kit No H109), and IgG (kit No H106) were determined by automatic biochemical analyzer (Hitachi 7020; Hitachi High Technologies, Inc., Ibaraki, Japan). The above kits were provided by Nanjing Jiangcheng Biotechnology Co., Ltd (Nanjing, China). The activities of serum malondialdehyde (MDA, kit No A003-1-2), glutathione peroxidase (GSH-Px, kit No A005-1-2), superoxide dismutase (SOD, kit No A001-1-2), and catalase (CAT, kit No A007-11) were determined by using respective assay kits (Nanjing Jiangcheng Biotechnology Co., Ltd, China).

\section{Statistical analysis}

The experimental data were analyzed by the general linear model procedure of SAS software (SAS Institute, 2003). When dietary therapy was significant $(\mathrm{p}<0.05)$, the mean values were compared by Duncan's multiple comparison program (SAS Institute, 2003) of SAS software. The probability level of $p<$
0.05 was considered to be statistically significant.

\section{RESULTS}

\section{Laying production performance}

As shown in Table 2, dietary PR supplementation tended to increase daily feed intake $(\mathrm{p}=0.0512)$. In addition, hens' egg production tended to increase with the increasing of dietary PR concentrations $(\mathrm{p}=0.0943)$, and the highest egg production was seen in the $1,200 \mathrm{mg} / \mathrm{kg}$ astaxanthin rich PR group. However, no significant differences were observed on average egg weight and feed conversion ratio among groups in the whole experimental period $(\mathrm{p}>0.05)$.

\section{Egg quality}

There was no effect of astaxanthin rich PR on Haugh units, albumen height, egg shape index, eggshell strength, and eggshell thickness at weeks 6 (Table $3, \mathrm{p}>0.05$ ). In our study, adding astaxanthin rich PR to the layer diet significantly enhanced the yolk color $(\mathrm{p}<0.05)$. Egg shell weight tended to increase with the increasing of dietary PR concentrations $(\mathrm{p}=0.0511)$.

\section{Antioxidant defenses}

The results showed that the SOD and CAT were significantly increased in 800 and $1,200 \mathrm{mg} / \mathrm{kg}$ astaxanthin rich $\mathrm{PR}$ treatments compared with the control treatment $(\mathrm{p}<0.05)$. However, the MDA concentration significantly decreased in 800 and $1,200 \mathrm{~g} / \mathrm{kg}$ astaxanthin rich PR treatments compared with the control treatment $(\mathrm{p}<0.05)$, and the suitable

Table 2. Effect of dietary astaxanthin rich Phaffia rhodozyma levels on production performance of laying hens after 6 weeks of feeding

\begin{tabular}{|c|c|c|c|c|c|}
\hline \multirow{2}{*}{ Items } & \multirow{2}{*}{ Control } & \multicolumn{3}{|c|}{ Phaffia rhodozyma supplemental levels (mg/kg) } & \multirow{2}{*}{ p-value } \\
\hline & & 800 & 1,200 & 16,00 & \\
\hline Average egg weight (g) & $64.51 \pm 1.781$ & $63.84 \pm 1.89$ & $63.31 \pm 2.11$ & $63.70 \pm 2.54$ & 0.5245 \\
\hline Egg production (\%) & $83.93 \pm 3.34$ & $87.35 \pm 3.62$ & $90.85 \pm 2.97$ & $86.95 \pm 3.13$ & 0.0943 \\
\hline Daily feed intake (g/bird) & $122.04 \pm 3.06$ & $123.65 \pm 3.08$ & $126.07 \pm 2.96$ & $126.02 \pm 3.11$ & 0.0512 \\
\hline Feed conversion ratio & $2.26 \pm 0.11$ & $2.15 \pm 0.1$ & $2.20 \pm 0.09$ & $2.225 \pm 0.09$ & 0.6567 \\
\hline
\end{tabular}

Table 3. Effect of dietary astaxanthin rich Phaffia rhodozyma levels on egg quality of laying hens

\begin{tabular}{|c|c|c|c|c|c|}
\hline \multirow{2}{*}{ Items } & \multirow{2}{*}{ Control } & \multicolumn{3}{|c|}{ Phaffia rhodozyma supplemental levels (mg/kg) } & \multirow{2}{*}{ p-value } \\
\hline & & 800 & 1,200 & 1,600 & \\
\hline Egg shell weight (g) & $6.69 \pm 0.54$ & $7.02 \pm 0.55$ & $6.9 \pm 0.59$ & $6.99 \pm 0.53$ & 0.0511 \\
\hline Egg-Shaped index & $1.30 \pm 0.04$ & $1.32 \pm 0.04$ & $1.32 \pm 0.04$ & $1.33 \pm 0.04$ & 0.7356 \\
\hline Eggshell Strength $\left(\mathrm{kg} / \mathrm{cm}^{2}\right)$ & $4.13 \pm 0.26$ & $4.26 \pm 0.23$ & $4.23 \pm 0.25$ & $4.21 \pm 0.21$ & 0.2333 \\
\hline Eggshell thickness (mm) & $0.32 \pm 0.02$ & $0.33 \pm 0.02$ & $0.33 \pm 0.02$ & $0.32 \pm 0.02$ & 0.4345 \\
\hline Albumen height (mm) & $6.80 \pm 0.36$ & $6.94 \pm 0.38$ & $6.99 \pm 0.39$ & $6.94 \pm 0.38$ & 0.6452 \\
\hline Yolk color & $6.67 \pm 0.48^{c}$ & $7.48 \pm 0.43^{b}$ & $7.75 \pm 0.45^{\mathrm{ab}}$ & $7.93 \pm 0.46^{\mathrm{a}}$ & 0.0021 \\
\hline Haugh unit & $80.15 \pm 4.26$ & $82.63 \pm 3.55$ & $82.52 \pm 3.8$ & $80.27 \pm 3.21$ & 0.2341 \\
\hline
\end{tabular}

\footnotetext{
${ }^{a-c}$ Means in a row without a common superscripts differ $(p<0.05)$.
} 
dosage was $1,200 \mathrm{mg} / \mathrm{kg}$ (Table 4).

\section{Immune defenses}

Table 5 shows the content of serum immunoglobulin in experimental hens. The results showed that the content of IgG in serum was significantly increased in groups 800 and 1,200 $\mathrm{mg} / \mathrm{kg}$ astaxanthin rich PR $(\mathrm{p}<0.05)$, which indicated that the appropriate amount of astaxanthin could improve the immunity of laying hens, and the optimal amount of astaxanthin was $1,200 \mathrm{mg} / \mathrm{kg}$.

\section{DISCUSSION}

In general, a traditional carotenoid source in poultry diets is $\beta$-carotene $[17,18]$. There is also a gradual trend to use Haematococcus astaxanthin to produce carotenoid-enriched eggs $[6,19]$. However, there is little research on the effect of astaxanthin rich PR in diets on laying hens, and our study was undertaken to help rectify this deficiency. In fact, the increase of daily egg production may relate to the fact that more feed was consumed with the increasing astaxanthin rich PR levels [20]. To date, the effect of carotenoid-enriched foods in poultry diets on performance of poultry is always a subject of debate. For example, feed intake has been reported to remain unchanged [21] or increase [22] upon astaxanthin-enriched foods supplementation. This discrepancy may be attributed to differences in diets composition and nutrition levels, and hen's age and strain among the experiments.

Adding carotenoids to poultry diets can increase the oxidative stability of poultry products [23]. However, this study shows that there was no effect of astaxanthin rich PR on Haugh units (HU), albumen height, egg shape index, egg- shell strength, and eggshell thickness at week 6. Egg yolk is the main carrier of egg flavor substances, and it is also an important index for consumers to evaluate the quality of eggs. The yolk color is an important index of egg quality. In our study, adding astaxanthin rich PR to the layer diet significantly enhanced the yolk color. A similar phenomenon was also found in other carotenoid studies [24]. Walker et al [19] studied the effects of palm toco and algae astaxanthin on egg quality parameters, and they found yolk color index was higher in algae astaxanthin group compared to palm toco group. Meanwhile, yolk color was changed (more red) by adding astaxanthin to laying hens' diets $[6,25]$. Generally, carotenoids are the main pigments in animals [26]. Astaxanthin can be directly stored in tissues without modification or biochemical transformation after being absorbed by animals [27], which makes the skin and eggs of some animals appear healthy golden yellow or red. However, the content of polyunsaturated fatty acid in yolk could affect the yolk color and it could be improved by the addition of microalgal astaxanthin to the diet of laying hens $[6,28]$.

Our research shows that astaxanthin red fermentation could significantly increase the activity of SOD and CAT and decrease the content of MDA in the serum of laying hens. Astaxanthin is a kind of carotene, one of the strongest natural antioxidants, which can effectively eliminate oxygen free radicals in LS-180 cells [29]. The molecular structure of astaxanthin is composed of many conjugated double bonds, and $\alpha$-hydroxyketone is composed of ketone group and hydroxyl group at the end of the conjugated double bond chain [30]. These molecular structure characteristics of astaxanthin determine that it has an active electronic effect, which can provide electrons to free radicals or attract un-

Table 4. Effect of dietary astaxanthin rich Phaffia rhodozyma levels on antioxidant defenses of laying hens

\begin{tabular}{|c|c|c|c|c|c|}
\hline \multirow{2}{*}{ Items } & \multirow{2}{*}{ Control } & \multicolumn{3}{|c|}{ Phaffia rhodozyma supplemental levels (mg/kg) } & \multirow{2}{*}{ p-value } \\
\hline & & 800 & 1,200 & 1,600 & \\
\hline $\mathrm{SOD}(\mathrm{U} / \mathrm{mL})$ & $138.75 \pm 2.76^{b}$ & $158.75 \pm 3.26^{\mathrm{a}}$ & $152.03 \pm 3.39^{\mathrm{a}}$ & $145.36 \pm 3.25^{\mathrm{ab}}$ & 0.0221 \\
\hline CAT $(\mathrm{U} / \mathrm{mL})$ & $6.46 \pm 0.26^{b}$ & $6.86 \pm 0.29^{a}$ & $6.85 \pm 0.24^{\mathrm{a}}$ & $6.71 \pm 0.33^{\mathrm{ab}}$ & 0.0012 \\
\hline $\mathrm{GSH}-\mathrm{Px}(\mu \mathrm{mol} / \mathrm{L})$ & $670.93 \pm 15.34$ & $702.93 \pm 13.43$ & $716.16 \pm 15.7$ & $718.15 \pm 11.7$ & 0.0538 \\
\hline $\operatorname{MDA}(\mathrm{nmol} / \mathrm{mL})$ & $2.90 \pm 0.41^{a}$ & $2.34 \pm 0.35^{b}$ & $2.26 \pm 0.38^{b}$ & $2.67 \pm 0.38^{a}$ & 0.0123 \\
\hline
\end{tabular}

SOD, superoxide dismutase; CAT, catalase; GSH-Px, glutathione peroxidase; MDA, malondialdehyde.

$a, b$ Means in a row without a common superscripts differ $(p<0.05)$.

Table 5. Effect of dietary astaxanthin rich Phaffia rhodozyma levels on immune defenses of laying hens

\begin{tabular}{|c|c|c|c|c|c|}
\hline \multirow{2}{*}{ Items } & \multirow{2}{*}{ Control } & \multicolumn{3}{|c|}{ Phaffia rhodozyma supplemental levels (mg/kg) } & \multirow{2}{*}{ p-value } \\
\hline & & 800 & 1,200 & 1,600 & \\
\hline $\operatorname{lgM}(\mathrm{mg} / \mathrm{L})$ & $7.39 \pm 0.31$ & $7.79 \pm 0.32$ & $8.06 \pm 0.31$ & $7.86 \pm 0.38$ & 0.2278 \\
\hline $\lg A(\mathrm{mg} / \mathrm{L})$ & $19.06 \pm 0.65$ & $20.01 \pm 0.64$ & $20.51 \pm 0.65$ & $20.11 \pm 0.64$ & 0.1643 \\
\hline $\operatorname{lgg}(\mathrm{mg} / \mathrm{L})$ & $77.23 \pm 4.27^{b}$ & $86.21 \pm 3.92^{\mathrm{a}}$ & $86.29 \pm 4.38^{a}$ & $84.34 \pm 4.05^{\mathrm{ab}}$ & 0.0341 \\
\hline
\end{tabular}

Ig, immunoglobulin.

a,b Means in a row without a common superscripts differ $(p<0.05)$. 
paired electrons of free radicals, so it can play the role of scavenging free radicals and antioxidation [31].

This experimental study shows that the content of $\operatorname{IgG}$ in serum was significantly increased, which indicated that the appropriate amount of astaxanthin could improve the immunity of laying hens. In vitro experiments showed that astaxanthin can improve the activity of $\mathrm{T}$ cells and the ability of peripheral blood monocytes to produce immunoglobulin [32]. In addition, it was found that the addition of astaxanthin rich PR to broiler diets had a positive effect on $\mathrm{T}$ cell proliferation and serum IgG content [33]. So, our results showed the increase in serum IgG content might be related to $\mathrm{T}$ cell proliferation. On the other hand, astaxanthin can protect the integrity of immune cells and ensure the normal immune response process [34], or it can improve the content of immunoglobulin by promoting the secretion of cytokines [35]. The mechanism of astaxanthin improving immune function may also be that it can promote the feeding and absorption of nutrients and provide necessary nutrients for the production of immune protein. This study shows that astaxanthin has no obvious effect on serum IgA and IgM levels, and its mechanism is not clear, which needs further study.

In summary, dietary astaxanthin rich PR supplementation had a remarkable influence on hens laying performance and egg quality, especially the improvement of yolk color. However, dietary astaxanthin rich PR supplementation in laying hens improved antioxidant defenses, and increased serum IgG contents. It suggested that astaxanthin rich PR can be utilized as a feed additive to improve the immunity and antioxidant capacity of laying hens.

\section{CONFLICT OF INTEREST}

We certify that there is no conflict of interest with any financial organization regarding the material discussed in the manuscript. Ge J is an employee of Shandong Zhongcheng feed Technology Co., Ltd.

\section{ACKNOWLEDGMENTS}

This work was supported by National Key Research and Development Plan (2016YFD0501403), and the Open Project Program of Key Laboratory of Feed Biotechnology of China, and Major Scientific and Technological Projects in Anhui Province (201904f06020004) and the Agricultural Science and High-level Talents Introduction Project of Anhui Institute of Science and Technology (DKYJ201701).

\section{REFERENCES}

1. Caballo C, Costi EM, Sicilia MD, Rubio S. Determination of supplemental feeding needs for astaxanthin and canthaxanthin in salmonids by supramolecular solvent-based microextraction and liquid chromatography-UV/VIS spectroscopy. Food Chem 2012;134:1244-9. https://doi.org/10.1016/j. foodchem.2012.03.051

2. Salatti-Dorado JA, García-Gómez D, Rodriguez-Ruiz V, Gueguen V, Pavon-Djavid G, Rubio S. Multifunctional green supramolecular solvents for cost-effective production of highly stable astaxanthin-rich formulations from Haematococcus pluvialis. Food Chem 2019;279:294-302. https://doi.org/10. 1016/j.foodchem.2018.11.132

3. Nishida Y, Yamashita E, Miki W. Quenching activities of common hydrophilic and lipophilic antioxidants against singlet oxygen using chemiluminescence detection system. Carotenoid Sci 2007;11:16-20.

4. Shimidzu N, Goto M, Miki W. Carotenoids as singlet oxygen quenchers in marine organisms. Fish Sci 1996;62:134-7. https:// doi.org/10.2331/fishsci.62.134

5. Visioli F, Artaria C. Astaxanthin in cardiovascular health and disease: mechanisms of action, therapeutic merits, and knowledge gaps. Food Funct 2017;8:39-63. https://doi.org/ 10.1039/C6FO01721E

6. Magnuson AD, Sun T, Yin R, et al. Supplemental microalgal astaxanthin produced coordinated changes in intrinsic antioxidant systems of layer hens exposed to heat stress. Algal Res 2018;33:84-90. https://doi.org/10.1016/j.algal.2018.04. 031

7. Ao X, Kim IH. Effects of astaxanthin produced by Phaffia rhodozyma on growth performance, antioxidant activities, and meat quality in Pekin ducks. Poult Sci 2019;98:4954-60. https://doi.org/10.3382/ps/pez256

8. Butler MW, McGraw KJ. Eggshell coloration reflects both yolk characteristics and dietary carotenoid history of female mallards. Funct Ecol 2013;27:1176-85. https://doi.org/10. $1111 / 1365-2435.12123$

9. Sunwoo HH, Gujral N. Chemical composition of eggs and egg products. In: Cheung PCK, Mehta BM, editors. Handbook of food chemistry. Berlin, Germany: Springer-Verlag Berlin Heidelberg; 2015. pp. 331-63.

10. Heng N, Gao S, Guo Y, et al. Effects of supplementing natural astaxanthin from Haematococcus pluvialis to laying hens on egg quality during storage at $4^{\circ} \mathrm{C}$ and $25^{\circ} \mathrm{C}$. Poult Sci 2020;99: 6877-83. https://doi.org/10.1016/j.psj.2020.09.010

11. Gao S, Li R, Heng N, et al. Effects of dietary supplementation of natural astaxanthin from Haematococcus pluvialis on antioxidant capacity, lipid metabolism, and accumulation in the egg yolk of laying hens. Poult Sci 2020;99:5874-82. https:// doi.org/10.1016/j.psj.2020.08.029

12. Akiba Y, Sato K, Takahashi K, et al. Meat color modification in broiler chickens by feeding yeast Phaffia rhodozyma containing high concentrations of astaxanthin. J Appl Poult Res 2001;10:154-61. https://doi.org/10.1093/japr/10.2.154 
13. Ohh M, Kim S, Pak SC, Chee K. Effects of dietary supplementation with astaxanthin on histamine induced lesions in the gizzard and proventriculus of broiler chicks. AsianAustralas J Anim Sci 2016;29:872-8. https://doi.org/10.5713/ ajas. 15.1020

14. Higuera-Ciapara I, Félix-Valenzuela L, Goycoolea FM. Astaxanthin: a review of its chemistry and applications. Crit Rev Food Sci Nutr 2006;46:185-96. https://doi.org/10.1080/1040 8690590957188

15. Capelli B, Bagchi D, Cysewski GR. Synthetic astaxanthin is significantly inferior to algal-based astaxanthin as an antioxidant and may not be suitable as a human nutraceutical supplement. Nutrafoods 2013;12:145-52. https://doi.org/10. 1007/s13749-013-0051-5

16. NRC. Nutrient requirements of poultry. 9th ed. Washington, DC, USA: National Academies Press; 1994.

17. Gong HZ, Wu M, Lang WY, et al. Effects of laying breeder hens dietary $\beta$-carotene, curcumin, allicin, and sodium butyrate supplementation on the growth performance, immunity, and jejunum morphology of their offspring chicks. Poult Sci 2020;99:151-62. https://doi.org/10.3382/ps/pez584

18. Ayaşan T, Karakozak E. Use of $\beta$-carotene in animal nutrition and its effects. Kafkas Univ Vet Fak Derg 2010;16:697-705.

19. Walker LA, Wang T, Xin H, Dolde D. Supplementation of laying-hen feed with palm tocos and algae astaxanthin for egg yolk nutrient enrichment. J Agric Food Chem 2012;60: 1989-99. https://doi.org/10.1021/jf204763f

20. Classen HL. Diet energy and feed intake in chickens. Anim Feed Sci Technol 2017;233:13-21. https://doi.org/10.1016/j. anifeedsci.2016.03.004

21. Magnuson AD, Sun T, Yin R, et al. Dietary supplementation of microalgal astaxanthin produced dose-dependent enrichments of the phytochemical and elevations of radical absorbance capacity in tissues and eggs of layer hens. J Anim Sci 2017;95:188. https://doi.org/10.2527/asasann.2017.379

22.Elwan HAM, Elnesr SS, Abdallah Y, Hamdy A, El-Bogdady AH. Red yeast (Phaffia rhodozyma) as a source of astaxanthin and its impacts on productive performance and physiological responses of poultry. Worlds Poult Sci J 2019;75:273-84. https:// doi.org/10.1017/S0043933919000187

23. Nabi F, Arain MA, Rajput N, et al. Health benefits of carotenoids and potential application in poultry industry: a review. J Anim Physiol Anim Nutr 2020;104:1809-18. https://doi. org/10.1111/jpn.13375

24. Moreno JA, Díaz-Gómez J, Fuentes-Font L, et al. Poultry diets containing (keto)carotenoid-enriched maize improve egg yolk color and maintain quality. Anim Feed Sci Technol 2020; 260:114334. https://doi.org/10.1016/j.anifeedsci.2019.114334
25.Johnson EA, Lewis MJ, Grau CR. Pigmentation of egg yolks with astaxanthin from the yeast Phaffia rhodozyma. Poult Sci 1980;59:1777-82. https://doi.org/10.3382/ps.0591777

26. Miyashita K. Function of marine carotenoids. In: Yoshikawa T, editor. Food factors for health promotion. Basel, Switzerland: Kanger; 2009. pp. 136-46. https://doi.org/10.1159/000212746

27.Lim KC, Yusoff FM, Shariff M, Kamarudin MS. Astaxanthin as feed supplement in aquatic animals. Rev Aquac 2018;10: 738-73. https://doi.org/10.1111/raq.12200

28. Tolba SA, Magnuson AD, Sun T, Lei XG. Dietary supplemental microalgal astaxanthin modulates molecular profiles of stress, inflammation, and lipid metabolism in broiler chickens and laying hens under high ambient temperatures. Poult Sci 2020; 99:4853-60. https://doi.org/10.1016/j.psj.2020.05.022

29. Hormozi M, Ghoreishi S, Baharvand P. Astaxanthin induces apoptosis and increases activity of antioxidant enzymes in LS-180 cells. Artif Cells Nanomed Biotechnol 2019;47:8915. https://doi.org/10.1080/21691401.2019.1580286

30.Zajac G, Machalska E, Kaczor A, Kessler J, Bour P, Baranska M. Structure of supramolecular astaxanthin aggregates revealed by molecular dynamics and electronic circular dichroism spectroscopy. Phys Chem Chem Phys 2018;20: 18038-46. https://doi.org/10.1039/C8CP01742E

31. Guan L, Liu J, Yu H, et al. Water-dispersible astaxanthin-rich nanopowder: preparation, oral safety and antioxidant activity in vivo. Food Funct 2019;10:1386-97. https://doi.org/10.1039/ C8FO01593G

32. Jyonouchi H, Sun S, Mizokami M, Gross MD. Effects of various carotenoids on cloned, effector-stage T-helper cell activity. Nutr Cancer 1996;26:313-24. https://doi.org/10.1080/016355 89609514487

33. Takimoto T, Takahashi K, Akiba Y. Effect of dietary supplementation of astaxanthin by Phaffia rhodozyma on lipid peroxidation, drug metabolism and some immunological variables in male broiler chicks fed on diets with or without oxidised fat. Br Poult Sci 2007;48:90-7. https://doi.org/10. 1080/00071660601156453

34. Wang X, Ma J, Bai X, Yan H, Qin C, Ren D. Antioxidant properties of astaxanthin produced by cofermentation between Spirulina platensis and recombinant Saccharomyces cerevisiae against mouse macrophage RAW 264.7 damaged by $\mathrm{H}_{2} \mathrm{O}_{2}$. Food Bioprod Process 2019;118:318-25. https://doi.org/10. 1016/j.fbp.2019.10.007

35. Cao J, Wang W. Effects of astaxanthin and esterified glucomannan on hematological and serum parameters, and liver pathological changes in broilers fed aflatoxin-B1-contaminated feed. Anim Sci J 2014;85:150-7. https://doi.org/10.1111/asj. 12103 